\title{
ANALISA KESESUAIAN LAHAN HUTAN RAKYAT DI DESA TAMBAK UKIR, KECAMATAN KENDIT KABUPATEN SITUBONDO
}

\author{
The Land Suitability Analysis Of Community Forest \\ In The Village Tambak Ukir, Subdistrict Kendit, Situbondo \\ Joko Sudibyo * dan/and A.Syaffari Kosasih ** \\ *Peneliti Fakultas Pertanian Universitas Jember, Jln Kalimantan, Jember \\ ** Peneliti Puslitbang Peningkatan Produktivitas Hutan \\ e-mail: safari_silvik@yahoo.co.idr
}

Naskah masuk : 10 Maret 2010; Naskah diterima : 3 Maret 2011

\begin{abstract}
The interest of farmers in Tambak Ukir village, Sub District of Kendit, Situbondo, East Java to develop dryland community-forest have increased. For that reason, it is necessary to select the species that suitable with the dryland. Each species has its maximum, minimum and optimum growth requirement. The research was conducted by comparing characteristic and quality of the land with the growth requirements of the plants. The result showed that sengon laut (Paraserianthes falcataria) is used in the land suitability under $\mathbf{S}$ category or moderately suitable for community forest for the sengon, as well as for Jati (Tectona grandis) and for Mahogani (Swietenia macrophylla). Whereas kacang komak ((Lablab purpureus), jagung (Zea mays) and kacang tanah (Arachis hypogea) are suitable only in the land with the slope $3 \%-8$ $\%$ is 22 (moderately suitable) category.
\end{abstract}

\section{Keywords: Dryland community forest, land suitability, growth requirement}

\begin{abstract}
ABSTRAK
Minat petani di desa Tambak Ukir, Kecamatan Kendit, Kabupaten Situbondo, Jawa Timur, untuk mengembangkan hutan rakyat di lahan kering telah meningkat. Untuk itu perlu dukungan pemilihan jenis tumbuhan agar sesuai dengan kondisi lahannya. Penelitian dilakukan dengan cara membandingkan karakteristik dan kualitas lahan dengan persyaratan tumbuh tanaman. Hasil analisa menunjukan lahan yang akan dimanfaatkan untuk membangun hutan rakyat termasuk kelas kesesuaian lahan potensial cukup sesuai (S2) untuk jenis sengon laut (Paraserianthes falcataria), jati (Tectona grandis) dan mahoni (Swietenia macrophylla). Sedangkan untuk kacang komak (Lablab purpreus), jagung (Zea mays) dan kacang tanah (Arachis hypogea) termasuk kelas kesesuaian lahan potensialnya cukup sesuai (S2) hanya pada lereng dengan kemiringan dari 3\% - $8 \%$.
\end{abstract}

\section{Kata kunci : Hutan rakyat lahan kering, kesesuaian lahan, persyaratan tumbuh}

\section{PENDAHULUAN}

Pemanfaatan lahan pada suatu wilayah yang tidak sesuai dengan potensi sumberdaya lahan akan berdampak timbulnya lahan kritis, sehingga terjadi degradasi lahan yang berakibat penurunan produktivitas. Lahan di Desa Tambak Ukir, Kecamatan Kendit, Kabupaten Situbondo merupakan salah satu wilayah lahan kering yang ada di kabupaten tersebut, terletak di daerah perbukitan dengan kriteria bentuk lahan menurut Direktorat Rehabilitasi dan Konservasi Tanah tahun 1997 termasuk dalam katagori datar sampai curam. Penggunaan lahan antara lain tegalan, pemukiman dan sawah tadah hujan.

Berdasarkan kondisi topografi, jenis tanah dan penggunaan lahan yang ada serta pengamatan di lapangan ternyata telah terjadi degradasi lahan yang cukup berat, hal ini nampak dari bekas-bekas erosi yang terjadi, dimana 
bebatuan muncul dipermukaan tanah, produksi tanaman pertanian menurun. Dengan kondisi tersebut diperlukan alternatif rancangan pengelolaan lahan, agar tingkat degradasi dapat ditekan dan produktivitas lahan dapat meningkat kembali. Model agroforestri dipandang mampu memperbaiki kondisi lingkungan, meningkatkan produktivitas dan sekaligus berfungsi konservasi (Van Schaik and Van Noordwijk, 2002; Agus et al., 2002 ). Guna menerapkan model agroforestri di lahan kering, seperti di desa Tambak Ukir agar memperoleh hasil optimal, maka pada tahap awal perlu mengetahui kesesuaian lahannya untuk dicocokan dengan tanaman hutan maupun tanaman semusim, yang akan dibudidayakan di daerah tersebut.

Kesesuaian lahan adalah kecocokan sebidang lahan untuk penggunaan lahan tertentu (Departemen Pertanian, 2001). Untuk mengetahui tingkatan dalam kesesuaian lahan dapat diperoleh dari hasil membandingkan antara karakteristik lahan dan kualitas lahan dengan kriteria persyaratan tumbuh tanaman. Karakteristik lahan yang dipergunakan sebagai penciri dalam metode klasifikasi kesesuaian lahan ini terdiri dari 3 (tiga) komponen lahan yaitu: 3 (tiga) karakteristik iklim, 10 (sepuluh) karakteristik tanah dan 5 (lima) karaketristik kondisi permukaan lahan.

Menurut Kartono et al (2001) dan Amien (1997) pengelolaan lahan yang memadukan komoditas tanaman pertanian dan kehutanan atau pola agroforestri, perlu didasarkan pada kesesuaian lahan, dapat dilakukan dengan melalui dua konsep yaitu pendekatan komoditas (comodity approach) dan pendekatan sumberdaya (land resource approach).

Tujuan penelitian ini adalah untuk (1) menyediakan informasi yang lengkap tentang kondisi sumberdaya lahan hutan rakyat di lokasi penelitian yang sesuai bagi tanaman pertanian dan kehutanan sehingga terbentuk hutan rakyat lahan kering dengan bentuk agroforestri, (2) prediksi tingkat kesuburan tanah dan kesesuaian lahan. Adapun manfaat penelitian ini adalah dapat dipakai sebagai dasar (1) untuk menentukan budidaya tanaman pertanian dan tanaman kehutanan yang sesuai dengan lokasi, dan (2) untuk rancangan pengelolaan lahan.

\section{METODE PENELITIAN}

Penelitian dan pengambilan contoh tanah dilakukan di lahan kelompok Tani Jaya Makmur
Dusun Tambak Ukir Desa Tambak Ukir, Kecamatan Kendit, Kabupaten Situbondo. Luas lahan yang digunakan \pm 5 hektar. Penentuan lokasi pengambilan contoh tanah dan pengamatan biofisik lahan dilakukan berdasarkan pendekatan bentang lahan dengan sistem transek. Hal ini dilakukan dengan pertimbangan bahwa arah lerengnya sama. Pengambilan contoh tanah dilakukan berdasarkan kriteria lereng menurut Direktorat Rehabilitasi dan Konservasi Tanah (1997) yaitu : datar ( 0 - $8 \%$ ), landai (8 - $15 \%$ ), Agak Curam $(15-25 \%)$ dan Curam $>25 \%$. Sampel tanah diambil pada kedalaman dari 0 sampai $30 \mathrm{~cm}$, masing-masing dari tiga titik yang berbeda pada setiap lereng. Analisa unsur-unsur fisik-kimia contoh tanah dilakukan di Laboratorium Fisika Tanah dan Laboratorium Kimia Tanah, Jurusan Tanah, Fakultas Pertanian Universitas Jember. Penelitian dilaksanakan pada bulan Mei sampai dengan Desember 2009.

Penilaian kesuburan tanah disesuaikan berdasarkan pedoman dari Pusat Penelitian Tanah dan Agroklimat (PPTA, 1994). Penilaian kesuburan tanah ini berdasarkan kombinasi dari unsur-unsur KTK, KB, P tersedia, K tersedia dan C-organik. Penilaian kesesuaian lahan dianalisa dengan teknik penyesuaian antara karakteristik lahan dan kualitas lahan berdasarkan Klasifikasi Kesesuaian Lahan dari (PPT, 2001) untuk tanaman semusim, sedang untuk tanaman tahunan berdasarkan Klasifikasi Kesesuaian Lahan dari (FAO, 1983).

Penilaian kesesuaian lahan dapat dibedakan menurut tingkatannya yaitu Ordo, Kelas, Sub-kelas dan Satuan Kesesuaian Lahan. Ordo kesesuaian lahan menggambartkan keadaan kesesuaian lahan secara global. Pada tingkat ini lahan dibagi menjadi dua yaitu ordo sesuai (S) dan ordo tidak sesuai (N). Lahan yang termasuk ordo sesuai (S) yaitu lahan yang dapat dipergunakan secara berkelanjutan untuk suatu tujuan tertentu tanpa atau sedikit resiko kerusakan terhadap sumberdaya lahannya. Lahan yang termasuk ordo tidak sesuai $(\mathrm{N})$ adalah lahan yang mempunyai pembatas sedemikian rupa sehingga tidak dapat dipergunakan untuk suatu tujuan tertentu. Pada tingkat kelas kesesuaian lahan menggambarkan keadaan tingkat kesesuaian lahan dalam ordo. Penentuan tingkat kelas pada setiap ordo didasarkan pada persyaratan dan pembatas penggunaan komoditas tertentu yang dinyatakan dengan kualitas dan karakteristik lahan. Pada orde sesuai dibagi menjadi tiga kelas kesesuaian lahan yaitu 
kelas sangat sesuai (S1), kelas cukup sesuai (S2) dan kelas sesuai marginal (S3). Pada orde tidak sesuai dibagi menjadi dua kesesuaian lahan yaitu kelas kelas tidak sesuai pada saat ini (N1) dan kelas tidak sesuai untuk selamanya (N2).

Lahan yang termasuk kelas sangat sesuai (S1) yaitu lahan yang tidak mempunyai pembatas yang cukup berat atau mempunyai pembatas yang tidak berpengaruh serta nyata terhadap produksi dan kualitas. Lahan yang termasuk kelas cukup sesuai (S2) yaitu lahan yang mempunyai pembatas yang agak berat, sehingga apabila tidak dilakukan usaha perbaikan tertentu atau meningkatkan masukan dari apa yang sudah tersedia, maka pembatas akan menurunkan produksi. Lahan yang termasuk kelas sesuai marginal (S3) yaitu lahan yang mempunyai pembatas yang cukup berat, untuk mempertahankan tingkat produksi yang menguntungkan diperlukan pengelolaan yang intensif. Pembatas secara nyata mengurangi produksi dan lebih meningkatkan masukan hara/pupuk.

Lahan yang termasuk kelas tidak sesuai saat ini (N1) yaitu lahan yang mempunyai pembatas sangat berat, tetapi masih mungkin untuk diatasi dengan tingkat pengelolaan dengan modal dan teknologi yang memadai. Lahan yang termasuk kelas tidak sesuai selamanya (N2) yaitu lahan yang mempunyai pembatas permanen dan menghalangi segala kemungkinan untuk penggunaan berkelanjutan. N2 sudah tidak mungkin untuk diperbaiki karena sifatnya yang permanen dan secara ekonomis tidak akan memberikan keuntungan.

Kesesuaian lahan pada tingkat sub kelas kesesuaian lahan menggambarkan keadaan tingkat dalam kelas yang didasarkan pada jenis pembatas yang menyebabkan lahan tersebut masuk dalam kelas kesesuaian lahan. Beberapa jenis pembatas yang biasa digunakan sebagai kriteria sub-kelas antara lain :

$\mathrm{t}=$ Rejim temperatur, dinyatakan sebagai karakteristik temperatur rata-rata tahunan yang terlalu rendah atau tinggi dari keadaan optimal yang dibutuhkan.

$\mathrm{w}=$ Ketersediaan air, dinyatakan sebagai karakteristik jumlah bulan kering dan curah hujan rata-rata tahunan.

$r=$ Media perakaran, sebagai karakteristik pembatasnya adalah drainase tanah, tekstur tanah permukaan dan kedalaman tanah efektif.

$\mathrm{f}=$ Retensi hara, sebagai karakteristik pembatasnya adalah kapasitas tukar kation rendah dan $\mathrm{pH}$ permukaan tanah tidak sesuai dengan kebutuhan tanaman

$\mathrm{n}=$ Ketersediaan hara, dinyatakan sebagai tingkat kesuburan tanah dengan karakteristik pembatasnya adalah kadar nitrogen, fosfot dan kalium tersedia.

$\mathrm{x}=$ Keracunan, ditetapkan berdasarkan salinitas atau kejenuhan Al pada lapisan bawah tanah (subsurface)

$\mathrm{s}=$ Terrain, merupakan keadaan permukaan tanah yang menyulitkan pengolahan tanah karena tingginya persentase lereng, banyaknya batu-batu kecil di permukaan tanah dan batu-batu besar pada kedalaman lapis olah,

Dengan kriteria di atas, maka dapat diketahui tingkat kesesuai lahan untuk suatu jenis tanaman tertentu berdasarkan karakteristik lahan dan persyaratan tumbuhnya sebagai mana contoh Tabel 1.

Pengelompokan tanaman ke dalam faktor dan kriteria karakteristik lahan, yang diperkirakan mempunyai persyaratan tumbuh yang sama dapat disatukan dalam satuan lahan.

Tabel (Table) 1. Kesesuai Lahan (Land Suitability)

\begin{tabular}{|l|c|c|c|c|c|}
\hline \multirow{2}{*}{$\begin{array}{c}\text { Karesteristik Lahan } \\
\text { (Land Characteristic) }\end{array}$} & \multicolumn{5}{c|}{$\begin{array}{c}\text { Kelas Kesesuaian } \\
\text { (Suitability Class) }\end{array}$} \\
\cline { 2 - 6 } & $\mathrm{S} 1$ & $\mathrm{~S} 2$ & $\mathrm{~S} 3$ & $\mathrm{~N} 1$ & $\mathrm{~N} 2$ \\
\hline $\begin{array}{l}\text { Temperatur ( } \mathrm{t}) \\
\text { Rata -rata tahunan }\left({ }^{\circ} \mathrm{C}\right)\end{array}$ & $20-<30$ & $30<35$ & $\mathrm{Td}$ & $\mathrm{Td}$ & $<21>35$ \\
\hline Ketersediaan air $(\mathrm{w})$ & $<3$ & $\mathrm{Td}$ & $\mathrm{Td}$ & $\mathrm{Td}$ & $=5$ \\
Bulan kering $(<75 \mathrm{~mm})$ & $>1250$ & $\mathrm{Td}$ & $\mathrm{Td}$ & $\mathrm{Td}$ & $<750$ \\
Curah hujan (mm) & & & & & \\
\hline
\end{tabular}


Tabel 1. Lanjutan (Continued).

\begin{tabular}{|c|c|c|c|c|c|}
\hline \multirow{2}{*}{$\begin{array}{l}\text { Karesteristik Lahan } \\
\text { (Land Characteristic) }\end{array}$} & \multicolumn{5}{|c|}{$\begin{array}{l}\text { Kelas Kesesuaian } \\
\text { (Suitability Class) }\end{array}$} \\
\hline & S1 & S2 & S3 & N1 & N2 \\
\hline $\begin{array}{l}\text { Media perakaran }(\mathrm{r}) \\
\text { Drainase tanah } \\
\text { Kedalaman tanah }(\mathrm{cm})\end{array}$ & $\begin{array}{l}\text { Baik } \\
=150\end{array}$ & $\begin{array}{l}\text { Sedang } \\
100 / 150\end{array}$ & $\begin{array}{l}\text { Agak buruk } \\
75-<100\end{array}$ & $\begin{array}{l}\text { Buruk } \\
50-<75\end{array}$ & $\begin{array}{l}\text { Sangat } \\
\text { Buruk } \\
<50\end{array}$ \\
\hline $\begin{array}{l}\text { Retensi hara ( } \mathrm{f}) \\
\text { tukar kation (me/100g) } \\
\text { pH tanah }\end{array}$ & $\begin{array}{l}25-40 \\
6,0-7,0\end{array}$ & $\begin{array}{l}17-24 \\
7,1-7,5\end{array}$ & $\begin{array}{l}5-16 \\
7,6-8,0\end{array}$ & $\begin{array}{l}10-15 \\
4,0-5,0\end{array}$ & $\begin{array}{l}<10 \\
<4,0\end{array}$ \\
\hline $\begin{array}{l}\text { Ketersediaan hara }(\mathrm{n}) \\
\text { a.N total } \\
\text { b. } \mathrm{P}_{2} \mathrm{O}_{2}(\mathrm{ppm}) \\
\text { c. } \mathrm{K}_{2} \mathrm{O}(\mathrm{mg} / 100 \mathrm{~g})\end{array}$ & $\begin{array}{l}\text { Tinggi } \\
46-60 \\
41-60\end{array}$ & $\begin{array}{l}\text { Sedang } \\
26-45 \\
21-40\end{array}$ & $\begin{array}{l}\text { Sedang } \\
26-45 \\
21-40\end{array}$ & $\begin{array}{l}\text { Rendah } \\
10-25 \\
10-20\end{array}$ & $\begin{array}{l}\text { Sangat } \\
\text { Rendah } \\
<10 \\
<10\end{array}$ \\
\hline $\begin{array}{l}\text { Keracunan (x ) } \\
\text { Kejenuhan Al ( \% ) }\end{array}$ & $<20$ & $20-35$ & $36-50$ & $51-60$ & $>60$ \\
\hline $\begin{array}{l}\text { Terain ( s ) } \\
\text { Lereng ( \% ) } \\
\text { Batuan permukaan ( \% ) } \\
\text { Singkapan batuan ( \% ) }\end{array}$ & $\begin{array}{l}<3 \\
<3 \\
<2\end{array}$ & $\begin{array}{l}3-8 \\
3-15 \\
2-10\end{array}$ & $\begin{array}{l}8-1516-25 \\
>15-40 \\
>10-25\end{array}$ & $\begin{array}{l}26-40 \\
\mathrm{Td} \\
>25-40\end{array}$ & $\begin{array}{l}>40 \\
>40 \\
>40\end{array}$ \\
\hline
\end{tabular}

Sumber: Petunjuk Teknis Evaluasi Pusat Penelitian Tanah dan Agroklimat, 1994.

Keterangan $\mathrm{Td}=$ Tidak berlaku

\section{HASIL DAN PEMBAHASAN}

\section{Karakteristik dan Kualitas Lahan}

Karakterisktik dan kualitas lahan pada lokasi penelitian diketahui dari sifat kimia dan fisik dari contoh tanah setiap kelerengan, hasil analisanya disajikan pada Tabel 2 dan 3 berikut.

Berdasarkan Tabel 2 dan 3 yang menunjukkan karakteristik dan kualitas lahan di Desa Tambak Ukir dapat dijelaskan sebagai berikut:

1. Sifat kimia tanah mempunyai kisaran dari sedang, rendah sampai sangat rendah menurut kriteria Pusat Penelitian Tanah dan Agroklimat (1994) yang disajikan dalam Lampiran 1. Oleh sebab itu untuk meningkatkan kesuburan tanah di desa Tambak Ukir diperlukan upaya pemupukan organik dan anorganik serta menerapkan pola-pola agroforestri.
2. Kadar lengas di tempat datar dan landai, lebih besar dibandingkan dengan yang curam. Hal tersebut menunjukkan bahwa kapasitas penyimpanan air di tempat datar dan landai lebih baik dibanding tempat yang curam. Demikian juga berat volume (BV), berat jenis partikel (BJP), dari total serta tekstur tanah silt loam dan clay masih lebih baik dari yang curam.

Kondisi sifat fisik dan kimia tanah seperti pada tempat yang datar sampai agak curam terjadi proses erosi akibat pemanfaatan lahan ini cukup berat, sehingga kandungan $\mathrm{C}$-org, $\mathrm{N}$ total berada pada tingkat rendah sampai sangat rendah, $\mathrm{K} 2 \mathrm{O}$ dari sedang sampai rendah di lahan datar sampai agak curam. Kandungan K2O, pada lahan yang landai lebih tinggi dari yang datar, kemungkinan ada perbedaan perlakuan pengolahan tanah dan pemupukan. 
Tabel (Table) 2. Hasil Analisis Sifat Kimia Tanah di lahan kering Desa Tambak Ukir (Result of Analysis of Soil Chemical Properties at dry land in Tambak Ukir Vilage)

\begin{tabular}{|c|c|c|c|c|c|c|c|c|}
\hline \multirow[t]{2}{*}{ No. } & \multirow[t]{2}{*}{ Lereng (Slopes) } & \multirow[t]{2}{*}{$\mathrm{pH}$} & C-org & $\mathrm{N}$ total & $\begin{array}{l}\mathrm{P} 2 \mathrm{O} 5 \\
\text { Bray }\end{array}$ & $\begin{array}{l}\mathrm{P} 2 \mathrm{O} 5 \\
\text { Olsen }\end{array}$ & $\mathrm{K} 2 \mathrm{O}$ & KTK \\
\hline & & & \multicolumn{2}{|c|}{$\%$} & \multicolumn{2}{|c|}{ ppm } & \multicolumn{2}{|c|}{$\mathrm{Me} / 100 \mathrm{gr}$} \\
\hline 1 & $\begin{array}{l}\text { Datar }(0-8 \%) \\
\text { (Flat } 0-8 \%)\end{array}$ & 6,1 & $\begin{array}{l}0,59 \\
\text { (SR) }\end{array}$ & $0,10(\mathrm{R})$ & $15,67(\mathrm{~S})$ & - & $0,22(\mathrm{R})$ & $\begin{array}{c}12,00 \\
(\mathrm{R})\end{array}$ \\
\hline 2 & $\begin{array}{l}\text { Landai }(8-15 \%) \\
\text { (Undulating } 9-15 \%)\end{array}$ & 5,8 & $\begin{array}{l}1,12 \\
(\mathrm{SR})\end{array}$ & $0,14(\mathrm{R})$ & $16,05(\mathrm{~S})$ & - & $0,35(\mathrm{~S})$ & $\begin{array}{c}22,80 \\
(\mathrm{~S})\end{array}$ \\
\hline 3 & $\begin{array}{l}\text { Agak Curam }(15-25 \%) \\
\text { (Rather steepy } 15-25 \%)\end{array}$ & 6,4 & $\begin{array}{l}0,53 \\
\text { (SR) }\end{array}$ & $0,10(\mathrm{SR})$ & $15,91(\mathrm{~S})$ & - & $0,22(\mathrm{R})$ & $\begin{array}{c}28,40 \\
(\mathrm{~T})\end{array}$ \\
\hline 4 & $\begin{array}{l}\text { Curam }(>25 \%) \\
(\text { Steepy }>25 \%)\end{array}$ & 6,7 & $1,26(\mathrm{R})$ & $0,13(\mathrm{R})$ & - & $18,82(\mathrm{~S})$ & $0,53(\mathrm{~S})$ & $\begin{array}{c}26,40 \\
(\mathrm{~T})\end{array}$ \\
\hline
\end{tabular}

Keterangan (Remarks) SR : Sangat Rendah (very low), S= Sedang (Medium) R : Rendah(Low), T: Tinggi (high)

Tabel (Table) 3. Hasil Analisis Sifat Fisika Tanah di Lahan Kering Desa Tambak Ukir (Result of Analysis of Soil Fisical Properties at dry land in Tambak Ukir Vilage)

\begin{tabular}{|c|c|c|c|c|c|c|c|c|c|}
\hline \multirow{3}{*}{ No } & \multirow{3}{*}{$\begin{array}{l}\text { Lereng } \\
\text { (Slopes) }\end{array}$} & \multirow{2}{*}{$\begin{array}{l}\text { Kadar } \\
\text { Lengas }\end{array}$} & \multirow{2}{*}{ BV } & \multirow[b]{2}{*}{ BJP } & \multirow{2}{*}{$\begin{array}{l}\text { Pori } \\
\text { Total }\end{array}$} & \multicolumn{3}{|c|}{ Tektur ( Tekture) } & \multirow{3}{*}{$\begin{array}{l}\text { Kelas } \\
\text { Tektur }\end{array}$} \\
\hline & & & & & & $\begin{array}{l}\text { Pasir } \\
\text { (Sand) }\end{array}$ & $\begin{array}{l}\text { Debu } \\
(A s h)\end{array}$ & $\begin{array}{l}\text { Liat } \\
\text { (Clay) }\end{array}$ & \\
\hline & & $\%$ & \multicolumn{2}{|c|}{$\mathrm{gr} / \mathrm{cm}^{3}$} & $\%$ & \multicolumn{3}{|c|}{$\%$} & \\
\hline 1 & $\begin{array}{l}\text { Datar }(0-8 \%) \\
(\text { Flat } 0-8 \%)\end{array}$ & 13,65 & 1,26 & 2,10 & 39,75 & 12,07 & 71,99 & 15,94 & $\begin{array}{c}\text { Silt } \\
\text { loam }\end{array}$ \\
\hline 2 & $\begin{array}{l}\text { Landai }(8-15 \%) \\
\text { (Undu lating } 9-15 \%)\end{array}$ & 18,62 & 1,44 & 2,04 & 29,66 & 8,59 & 28,94 & 62,47 & Clay \\
\hline 3 & $\begin{array}{l}\text { Agak Curam }(15-25 \%) \\
\text { (Rather steepy } 15-25 \%)\end{array}$ & 11,58 & 1,36 & 2,05 & 33,74 & 20,83 & 35,71 & 43,46 & Clay \\
\hline 4 & $\begin{array}{l}\text { Curam }(>25 \%) \\
(\text { Steepy }>25 \%)\end{array}$ & 2,47 & & 2,31 & & 51,65 & 30,26 & 18,09 & Loam \\
\hline
\end{tabular}

\section{Klasifikasi Kesesuaian Lahan di Lokasi Penelitian}

Hasil penilaian kesesuaian lahan dengan metode faktor pembatas pertumbuhan pada tanaman pertanian dan kehutananan di Tambak Ukir, disajikan pada Tabel 4 dan 5.

Berdasarkan Tabel 4, untuk tanaman pertanian (Jagung, Kacang Tanah dan Kacang Komak) termasuk kelas kesesuaian lahan potensial, cukup sesuai (S2) pada kemiringan kurang dari $15 \%$. Untuk mencegah erosi dan mengurangi aliran permukaan pembuatan guludan diperlukan, agar kapasitas air infiltrasi meningkat untuk memenuhi kebutuhan air yang cukup bagi tanaman. Pupuk perlu diberikan mengingat ketersediaan hara dan kesuburan tanahnya masih rendah (S3n).

Berdasarkan Tabel 5, untuk tanaman kehutanan termasuk kelas kesesuaian lahan potensial, cukup sesuai (S2). Walaupun demikian perlu dibuatkan usaha konservasi tanah, pengelohan tanah dan pembuatan embung, karena adanya faktor ketersedian air dan retensi hara menjadi faktor pembatas (Swf dan Sfw).
Selain itu pada awal tanam perlu dilakukan pemupukan berimbang dengan pupuk organik/kandang sebanyak 3 - $5 \mathrm{Kg}$ pertanaman, untuk memperbaiki faktor-faktor pembatas, dan upaya rehabilitasi (Firmansyah et al., 2008).

\section{Alternatif Rancangan Pengelolaan Lahan}

Berdasarkan Tabel 4 dan 5 diatas, maka pemanfaatan lahan pertama-tama harus disesuaikan dengan kelas kemampuan lahannya. Jika didasarkan pada kesesuaian lahannya, maka sebaiknya ditanami tanaman kacang komak, jagung dan kacang tanah dengan faktor pembatas adalah kemiringan lahan dan bahan organik yang sangat rendah. Untuk ketiga tanaman tersebut termasuk cukup sesuai dan produksi tanaman termasuk sedang.

Untuk mempertinggi produksi tanaman maka perlu dilakukan penambahan pupuk organik dan anorganik serta pembuatan terasering, sebagai usaha konservasi tanah dan air. Konservasi tanah dan air ini dimaksudkan untuk mengatur aliran permukaan, sehingga tidak menimbulkan erosi dan meningkatkan peresapan air. Terasering 
Tabel(Table) 4. Klasifikasi Kesesuaian Lahan Kelompok Tanaman Pertanian di Hutan Rakyat Desa Tambak Ukir.(Land Suitability Classification of Agricultural Crops Group at Forest Community in Kendit Vilage)

\begin{tabular}{|c|c|c|c|c|}
\hline \multirow{2}{*}{ Lereng (Slopes ) } & \multirow{2}{*}{$\begin{array}{l}\text { Kesesuaian lahan } \\
\text { (Land suitability) }\end{array}$} & \multicolumn{3}{|c|}{ Jenis Tanaman (plant species) } \\
\hline & & Kacang komak & Jagung & Kacang tanah \\
\hline \multirow{3}{*}{$\begin{array}{l}\text { Datar }(0-8 \%) \\
(\text { Flat } 0-8 \%)\end{array}$} & $\begin{array}{l}\text { Kelas Kesesuaian Aktual } \\
\text { (actual suitability class) }\end{array}$ & $\mathrm{S} 3 \mathrm{n}$ & $\mathrm{S} 3 \mathrm{n}$ & S3n \\
\hline & $\begin{array}{l}\text { Faktor Pembatas } \\
\text { (limited factor) }\end{array}$ & $\begin{array}{l}\text { Ketersediaan } \\
\text { hara (nutriens } \\
\text { supplay) }\end{array}$ & $\begin{array}{l}\text { Ketersediaan } \\
\text { hara (nutriens } \\
\text { supplay) }\end{array}$ & $\begin{array}{c}\text { Ketersediaan } \\
\text { hara (nutriens } \\
\text { supplay) }\end{array}$ \\
\hline & $\begin{array}{l}\text { Kelas Kesesuaian Potensial } \\
\text { (potential suitability class ) }\end{array}$ & $\mathrm{S} 2$ & $\mathrm{~S} 2$ & $\mathrm{~S} 2$ \\
\hline \multirow{3}{*}{$\begin{array}{l}\text { Landai }(8-15 \%) \\
(\text { Undu lating } 8-15 \\
\%)\end{array}$} & $\begin{array}{l}\text { Kelas Kesesuaian Aktual ( } \\
\text { actual suitability class ) }\end{array}$ & S3n & S3n & S3n \\
\hline & $\begin{array}{l}\text { Faktor Pembatas } \\
\text { (limited factor) }\end{array}$ & $\begin{array}{l}\text { Ketersediaan } \\
\text { hara (nutriens } \\
\text { supplay) }\end{array}$ & $\begin{array}{l}\text { Ketersediaan } \\
\text { hara (nutriens } \\
\text { supplay) }\end{array}$ & $\begin{array}{c}\text { Ketersediaan } \\
\text { hara (nutriens } \\
\text { supplay) }\end{array}$ \\
\hline & $\begin{array}{l}\text { Kelas Kesesuaian Potensial } \\
\text { (potential suitability class ) }\end{array}$ & $\mathrm{S} 2$ & $\mathrm{~S} 2$ & $\mathrm{~S} 2$ \\
\hline \multirow{3}{*}{$\begin{array}{l}\text { Agak Curam } \\
(15-25 \%) \\
(\text { Rather steepy } 15-25 \\
\%)\end{array}$} & $\begin{array}{l}\text { Kelas Kesesuaian Aktual } \\
\text { (actual suitability class ) }\end{array}$ & $\mathrm{S} 3 \mathrm{~s}$ & S3s & S3s \\
\hline & $\begin{array}{l}\text { Faktor Pembatas } \\
\text { (limited factor) }\end{array}$ & $\begin{array}{l}\text { Lereng } \\
\text { (Slope) }\end{array}$ & $\begin{array}{l}\text { Lereng } \\
\text { (Slope) }\end{array}$ & $\begin{array}{l}\text { Lereng } \\
\text { (Slope) }\end{array}$ \\
\hline & $\begin{array}{l}\text { Kelas Kesesuaian Potensial } \\
\text { (potential suitability class ) }\end{array}$ & S3 & S3 & $\mathrm{S} 3$ \\
\hline \multirow{3}{*}{$\begin{array}{l}\text { Curam }(>25 \%) \\
(\text { Steepy }>25 \%)\end{array}$} & $\begin{array}{l}\text { Kelas Kesesuaian Aktua } \\
\text { (actual suitability class ) }\end{array}$ & $\mathrm{N}$ & $\mathrm{N}$ & $\mathrm{N}$ \\
\hline & $\begin{array}{l}\text { Faktor Pembatas } \\
\text { (limited factor) }\end{array}$ & $\begin{array}{l}\text { Lereng } \\
\text { (Slope) }\end{array}$ & $\begin{array}{l}\text { Lereng } \\
\text { (Slope) }\end{array}$ & $\begin{array}{l}\text { Lereng } \\
\text { (Slope) }\end{array}$ \\
\hline & $\begin{array}{l}\text { Kelas Kesesuaian Potensial } \\
\text { (potential suitability class ) }\end{array}$ & $\mathrm{N}$ & $\mathrm{N}$ & $\mathrm{N}$ \\
\hline
\end{tabular}

hakekatnya merupakan usaha mengubah kecuraman lereng melalui pembuatan sengkedan. Pembuatan sengkedan ini, untuk memperpendek jarak aliran, serta memperkecil derajat kemiringan (slope), sehingga air yang terinfiltrasi ke dalam tanah bertambah.

Hal yang perlu diusahakan untuk konservasi lahan pada hutan rakyat di Desa Tambak Ukir dapat dilakukan dengan cara teknis atau vegetasi yaitu dengan:

a. Penambahan Tanaman Penutup Tanah

Tanaman penutup tanah merupakan tanaman yang ditanam bersamaan dengan tanaman pokok (sengon, jati, mahoni). Tanaman penutup tanah berfungsi untuk mencegah erosi, menambah bahan organik tanah dan memperbesar kemampuan tanah untuk menyerap dan menahan air hujan yang jatuh. Jenis tanaman penutup tanah sebaiknya jenis kacang-kacangan yang bernilai ekonomi (kacang komak dan kacang tanah)

\section{b. Pembuatan Rorak}

Pembuatan rorak merupakan sistem konservasi tanah dan air. Jarak antar rorak disesuaikan dengan kondisi lapangan yaitu lebar rorak $0,5 \mathrm{~m}$. Semakin lebar rorak semakin efektif mengendalikan erosi.

c. Penanaman dalam strip

Tindakanan ini merupakan suatu sistem bercocok tanam dengan cara menanam beberapa jenis tanaman dalam strip-strip secara berselang seling pada bidang olah dan ditanam memotong lereng atau menurut kontur, tujuannya untuk mengurangi erosi dengan meninggikan tanah di jalur tananamn. Tanaman yang digunakan adalah tanaman jagung dan kacang tanah

\section{d. Pergiliran tanaman}

Cara penting lainnya untuk konservasi tanah dan air ialah dengan pergiliran tanaman yaitu sistem penanaman berbagai tanaman secara bergilir dalam urutan waktu tertentu pada suatu 
Tabel (Table) 5. Klasifikasi Kesesuaian Lahan Kelompok Tanaman Hutan di Desa Tambak Ukir .(Land Suitability Classification of Forest Plantation Group at Forest Community in Tambak Ukir Vilage).

\begin{tabular}{|c|c|c|c|c|}
\hline \multirow{2}{*}{ Lereng (Slopes) } & \multirow{2}{*}{$\begin{array}{l}\text { Kesesuaian lahan } \\
\text { (Land suitability) }\end{array}$} & \multicolumn{3}{|c|}{ Jenis Tanaman } \\
\hline & & Jati & Sengon & Mahoni \\
\hline \multirow[t]{3}{*}{$\begin{array}{l}\text { Datar }(0-8 \%) \\
\text { (Flat } 0-8 \%)\end{array}$} & $\begin{array}{l}\text { Kelas Kesesuaian Aktual } \\
\text { ( actual suitability class) }\end{array}$ & S2wf & S2wf & S2wf \\
\hline & $\begin{array}{l}\text { Faktor Pembatas } \\
\text { (limited factor) }\end{array}$ & $\begin{array}{l}\text { Iklim,Keterse } \\
\text { dian } \\
\text { hara(climate, } \\
\text { nutrients } \\
\text { supplay) }\end{array}$ & $\begin{array}{l}\text { Iklim,Keter } \\
\text { sedian } \\
\text { hara(climate, } \\
\text { nutrients } \\
\text { supplay) }\end{array}$ & $\begin{array}{l}\text { Iklim,Keter } \\
\text { sedian } \\
\text { hara(climate, } \\
\text { nutrients } \\
\text { supplay) }\end{array}$ \\
\hline & $\begin{array}{l}\text { Kelas Kesesuaian Potensial } \\
\text { (potential suitability class ) }\end{array}$ & $\mathrm{S} 2$ & $\mathrm{~S} 2$ & $\mathrm{~S} 2$ \\
\hline \multirow{3}{*}{$\begin{array}{l}\text { Landai }(8-15 \%) \\
(\text { Undu lating } 8-15 \\
\%)\end{array}$} & $\begin{array}{l}\text { Kelas Kesesuaian Aktual } \\
\text { ( actual suitability class) }\end{array}$ & $\mathrm{S} 2 \mathrm{fw}$ & S2wf & S2wf \\
\hline & $\begin{array}{l}\text { Faktor Pembatas } \\
\text { (limited factor) }\end{array}$ & $\begin{array}{c}\text { Iklim } \\
\text { (climate) }\end{array}$ & $\begin{array}{c}\text { Iklim } \\
\text { (climate) }\end{array}$ & $\begin{array}{c}\text { Iklim } \\
\text { (climate) }\end{array}$ \\
\hline & $\begin{array}{l}\text { Kelas Kesesuaian Potensial } \\
\text { (potential suitability class ) }\end{array}$ & $\mathrm{S} 2$ & $\mathrm{~S} 2$ & $\mathrm{~S} 2$ \\
\hline \multirow{3}{*}{$\begin{array}{l}\text { Agak Curam } \\
(15-25 \%) \\
(\text { Rather steepy } 15- \\
25 \%)\end{array}$} & $\begin{array}{l}\text { Kelas Kesesuaian Aktual } \\
\text { ( actual suitability class ) }\end{array}$ & S2ws & S2ws & S2ws \\
\hline & $\begin{array}{l}\text { Faktor Pembatas } \\
\text { (limited factor) }\end{array}$ & $\begin{array}{l}\text { Iklim, lereng } \\
\text { (climate,slope) }\end{array}$ & $\begin{array}{l}\text { Iklim, lereng } \\
\text { (climate,slope) }\end{array}$ & $\begin{array}{l}\text { Iklim, lereng } \\
\text { (climate,slope) }\end{array}$ \\
\hline & $\begin{array}{l}\text { Kelas Kesesuaian Potensial } \\
\text { (potential suitability class ) }\end{array}$ & $\mathrm{S} 2$ & $\mathrm{~S} 2$ & $\mathrm{~S} 2$ \\
\hline \multirow{3}{*}{$\begin{array}{l}\text { Curam }(>25 \%) \\
(\text { Steepy }>25 \%)\end{array}$} & $\begin{array}{l}\text { Kelas Kesesuaian Aktual } \\
\text { ( actual suitability class ) }\end{array}$ & S2ws & S2ws & S2ws \\
\hline & $\begin{array}{l}\text { Faktor Pembatas } \\
\text { (limited factor) }\end{array}$ & $\begin{array}{l}\text { Iklim, lereng } \\
\text { (climate,slope) }\end{array}$ & $\begin{array}{l}\text { Iklim, lereng } \\
\text { (climate,slope) }\end{array}$ & $\begin{array}{l}\text { Iklim, lereng } \\
\text { (climate,slope) }\end{array}$ \\
\hline & $\begin{array}{l}\text { Kelas Kesesuaian Potensial } \\
\text { (potential suitability class ) }\end{array}$ & $\mathrm{S} 2$ & $\mathrm{~S} 2$ & $\mathrm{~S} 2$ \\
\hline
\end{tabular}

bidang lahan. Pada lahan kering yang berlereng atau tanahnya miring pergiliran tanaman yang efektif untuk mencegah erosi adalah antara tanaman penghasil bahan pangan (kacang tanah) dengan tanaman penutup tanah untuk pakan ternak.

\section{e. Menambah tanaman penguat teras}

Tanaman yang memenuhi syarat sebagai penguat teras adalah (a) mempunyai sistem perakaran intensif, sehingga mampu mengikat air, (b) tahan pangkas sehingga tidak menaungi tanaman utama, (c) bermanfaat dalam menyuburkan tanah maupun sebagai penghasil makanan ternak. Tanaman penguat teras yang dianjurkan ditanam antara lain lamtorogung, gamal, akasia, dan rumput benggala. f. Penggunaan bahan organik dan mulsa

Adalah salah satu cara untuk memperbaiki struktur tanah, mempertinggi kemampuan tanah dalam menyerap air. Yaitu dengan menggunakan pupuk organik, berupa pupuk hijau atau pupuk kandang serta penggunaan sisa-sisa tanaman yang diletakkan di atas tanah sebagai serasah (mulsa) yang dapat mempertahankan kelembaban tanah. Pemberian pupuk organik menurut Widriani et al., (2009) merupakan usaha pembenahan tanah yang paling baik diantaraanya menyediakan kembali unsur hara bagi tanaman. Dengan pupuk organik penguapan air tanah dapat diperkecil sehingga air tanah dan unsur hara makro maaupun mikro tetap tersedia bagi tumbuhnya tanaman. 


\section{KESIMPULAN DAN SARAN}

\section{A. Kesimpulan}

Kesesuaian jenis tanaman kehutanan seperti sengon laut, jati dan mahoni termasuk kelas potensialnya cukup sesuai (S2). Demikian juga tanaman pertanian yaitu kacang komak, jagung dan kacang tanah termasuk kelas kesesuaian lahan potensialnya cukup sesuai di lahan yang datar sampai landai ( 3-8 \% ). Untuk meningkatkan produktivitas, diperlukan usaha konservasi tanah berupa pembuatan terasering dan pembuatan rorak untuk menampung tanah yang tererosi, sedangkan faktor iklim menjadi faktor pembatas. Selain itu pada awal tanam perlu dilakukan pemupukan berimbang dan pengolahan tanah untuk membuang bebatuan di lobang tanam yang akan ditanami.

\section{B. Saran}

Model pengelolaan agroforestry dianjurkan dengan pola menanam jenis tanaman pangan (jagung dan kacang tanah) di waktu musim hujan secara bergilir diantara larikan tanaman hutan, dan pada saat musim kemarau tanamnan pangannya diganti dengan kacang komak atau tanaman pakan ternak yang tahan kering.

\section{DAFTAR PUSTAKA}

Agus, F. Ginting, A.N dan Van Noordwijk, M. 2002 . Pilihan Teknologi Agroforestri/Konservasi Tanah untuk Areal Pertanian Berbasis Kopi di Sumberjaya, Lampung Barat. ICRAF Southeast Asia.

Amien, L.I, 1997. Karakteristik dan Analisis Agroekologi. Materi Apresiasi Metodologi Analisis Zona Agroekologi untuk Pengembangan Sumberdaya Lahan Pertanian. Badan Litbang Pertanian.

CSR/FAO Staff, 1983. Recoonaissance Land Resource Surveys $1: 250.000$ Scale Atlas Format Precedures. Manual 4, Version 1. Centre for Soil Research, Ministry of Agriculture Governmanet of Indonesia United Nations Development Programme and Food and Agriculture Organization. Bogor. Indonesia.
Departemen Pertanian, 2001. Kriteria Kesuaian Lahan untuk Komoditas Pertanian. Puslitanak dan Badan Penelitian dan Pengembangan Pertanian.

Direktorat Rehabilitasi dan Konservasi Tanah, 1997. Loka Karya Penentuan Kriteria Lahan Kritis.

FAO, 1976. A Frame Work for Land Evaluation. FAO Soil Bulletin No. 32, Rome.

Firmansyah,M., Sudarsono, Pawitan, Djuniwati dan Djayakirana, 2008. Karakterisasi dan Resilensi Tanah Terdegradasi di Lahan Kering Kalimantan Tengah. Jurnal Tanah dan Iklim No.27. Balai Besar Penelitian dan Pengembangan Sumberdaya Lahan Pertanian. Badan Litbang Pertanian

Kartono,G., Saraswati dan Suyamto, 2001. Peranan Zona Agroekologi dalam Pembangunan Wilayah Pertanian Jawa Timur. Materi Apresiasi Teknologi Pertanian Jawa Timur. Balai Pengkajian Teknologi Pertanian Karang Ploso.

Pusat Penelitian Tanah, 1983. Terms of Refernce Klasifikasi Kesesuaian Lahan. Pusat Penelitian Tanah. Proyek Penelitian Pertanian Menuju Transmigrasi (P3MT). Bogor

Pusat Penelitian Tanah dan Agroklimat. 1994. Laporan Teknis No 7, Versi 1,0 April 1994;.

Van Schaik,C.P dan Van Noordwijk,M. 2002. Agroforestry and Biodiversity are they compatible? In: Sitompul, S.M. dan Utami, S.R. (eds) Akar Pertanian Sehat, Konsep dan Pemikiran. Rangkuman Makalah Pertanian Sehat. Jurusan Tanah Fakultas Pertanian, Universitas Brawijaya.

Widiriani,R. Sabiham, Hadi Sutjahyo dan Las, 2009. Analisis Berkelanjutan Usaha Tani di Kawasan Rawan Erosi (Studi Kasus di Kecamatan Lembang Kabupaten Bandung Barat dan Kecamatan Dongko, Kabupaten Trenggalek) Jurnal Tanah dan Iklim No 29. Balai Besar Penelitian dan Pengembangan Sumberdaya Lahan Pertanian. Badan Litbang Pertanian. 
Lampiran (Appendix) 1. Kriteria Penilaian Sifat Kimia Tanah

\begin{tabular}{|c|c|c|c|c|c|}
\hline Sifat Tanah & $\begin{array}{l}\text { Sangat } \\
\text { Rendah }\end{array}$ & Rendah & Sedang & Tinggi & $\begin{array}{l}\text { Sangat } \\
\text { Tinggi }\end{array}$ \\
\hline C (\%) & $<<1,00$ & $1,00-2,00$ & $2,01-3,00$ & $3,01-5,00$ & $>5,0$ \\
\hline $\mathrm{N}(\%)$ & $<0,10$ & $0,10-0,20$ & $0,21-0,50$ & $0,51-0,75$ & $>0,75$ \\
\hline $\mathrm{C} / \mathrm{N}$ & $<5$ & $5-10$ & $11-15$ & $16-25$ & $>25$ \\
\hline $\mathrm{P}_{2} \mathrm{O}_{5} \mathrm{HCl} 25 \%\left(\mathrm{mg} / 100_{\mathrm{g}}\right)$ & $<10$ & $10-20$ & $21-40$ & $41-60$ & $>60$ \\
\hline $\mathrm{P}_{2} \mathrm{O}_{5}$ Bray I $(\mathrm{ppm})$ & $<10$ & $10-15$ & $16-25$ & $26-35$ & $>35$ \\
\hline $\mathrm{P}_{2} \mathrm{O}_{5}$ Olsen (ppm) & $<10$ & $10-25$ & $26-45$ & $46-60$ & $>60$ \\
\hline $\mathrm{K}_{2} \mathrm{O} \mathrm{HCl} 25 \%(\mathrm{mg} / 100 \mathrm{~g})$ & $<10$ & $10-20$ & $21-40$ & $41-60$ & $>60$ \\
\hline KTK (me/100g) & $<5$ & $5-16$ & $17-24$ & $25-40$ & $>40$ \\
\hline $\begin{array}{l}\text { Susunan kation : } \\
\mathrm{K} \text { (me } / 100 \mathrm{~g})\end{array}$ & $<0,1$ & $0,1-0,2$ & $0,3-0,5$ & $0,6-1,0$ & $>1,0$ \\
\hline $\mathrm{Na}(\mathrm{me} / 100 \mathrm{~g})$ & $<0,1$ & $0,1-0,3$ & $0,4-0,7$ & $0,8-1,0$ & $>1,0$ \\
\hline $\mathrm{Mg}(\mathrm{me} / 100 \mathrm{~g})$ & $<0,4$ & $0,4-1,0$ & $1,1-2,0$ & $2,1-8,0$ & $>8,0$ \\
\hline $\mathrm{Ca}(\mathrm{me} / 100 \mathrm{~g})$ & $<2$ & $2-5$ & $6-10$ & $11-20$ & $>20$ \\
\hline Kejenuhan Basa (\%) & $<20$ & $20-35$ & $36-50$ & $51-70$ & $>70$ \\
\hline Kejenuhan Alumunium (\%) & $<10$ & $10-20$ & $21-30$ & $31-60$ & $>60$ \\
\hline $\begin{array}{l}\text { Sangat Masam } \\
<4,5\end{array}$ & $\begin{array}{l}\text { Masam } \\
4,5-5,5\end{array}$ & $\begin{array}{ll}\text { sam } & \text { Netral } \\
.5 & 6,6-7,5\end{array}$ & $\begin{array}{r}\text { Agak Alk } \\
7,6-8\end{array}$ & $\begin{array}{r}\text { Alkalis } \\
>8,5\end{array}$ & \\
\hline
\end{tabular}

Sumber : Pusat Penelitian Tanah Agroklimat, 1994 (Laporan Teknis No.7, Versi 1,0 April 1994; LREP-II/C) 